\title{
Co-occurrence patterns of litter decomposing communities in mangroves indicate a robust community resistant to disturbances
}

\author{
Rodrigo G Taketani ${ }^{\text {Corresp., }}{ }^{1,2}$, Marta A Moitinho $^{2}{ }^{,}$Tim H Mauchline ${ }^{3}$, Itamar S Melo ${ }^{2}$ \\ 1 Department of Soil Sciences, "Luiz de Queiroz" College of Agriculture,, University of São Paulo, Piracicaba, SP, Brazil \\ 2 Laboratory of Environmental Microbiology, Embrapa Environment, Brazilian Agricultural Research Corporation-EMBRAPA, Jaguariuna, SP, Brazil \\ 3 Sustainable Agriculture Sciences, Rothamsted Research, Harpenden, United Kingdom \\ Corresponding Author: Rodrigo G Taketani \\ Email address: rgtaketani@usp.br
}

Background. Mangroves are important coastal ecosystems known for high photosynthetic productivity and ability to support marine food chains through supply of dissolved carbon or particular organic matter. Most of the carbon found in mangroves is produced by its vegetation and is decomposed in root associated sediment. This process involves a tight interaction between microbial populations, litter chemical composition, and environmental parameters. Here, we study the complex interactions found during litter decomposition in mangroves by applying network analysis to metagenomic data. Methods. Leaves of three species of mangrove trees typically found in the southeast of Brazil (Rhizophora mangle, Laguncularia racemosa, and Avicennia schaueriana) were collected in separate litter bags and left on three different mangroves for 60 days. These leaves were subsequently used for metagenome sequencing using Ion Torrent technology. Sequences were annotated in MG-RAST and used for network construction using MENAp. Results. The most common phyla were Proteobacteria (classes Gamma and Alphaproteobacteria) followed by Firmicutes (Clostridia and Bacilli). The most abundant protein clusters were associated with the metabolism of carbohydrates, amino acids, and proteins. Non-metric multidimensional scaling of the metagenomic data indicated that substrate (i.e., tree species) did not significantly select for a specific community. Both networks exhibited scale-free characteristics and small world structure due to the low mean shortest path length and high average clustering coefficient. These networks also had a low number of hub nodes most of which were module hubs. Discussion. This study demonstrates that under different environmental pressures (i.e., plant species or mangrove location) the microbial community associated with the decaying material forms a robust and stable network. 
1 Co-occurrence patterns of litter decomposing communities in mangroves indicate a robust 2 community resistant to disturbances

3 Rodrigo G. Taketani ${ }^{1,2 *}$, Marta A. Moitinho ${ }^{1}$, Tim H. Mauchline ${ }^{3}$, Itamar S. Melo ${ }^{1}$

41 - Laboratory of Environmental Microbiology, Embrapa Environment. Brazilian Agricultural

5 Research Corporation-EMBRAPA, Jaguariúna, São Paulo, Brazil.

6 2- Department of Soil Sciences, "Luiz de Queiroz” College of Agriculture, University of São

7 Paulo, Av. Pádua Dias, 11 - Cx. Postal 9, Piracicaba, SP, Brazil, ZC 13418-900

8 3- Sustainable Agriculture Sciences, Rothamsted Research, Harpenden, United Kingdom.

9 * - Corresponding author: R.G. Taketani. Department of Soil Sciences, "Luiz de Queiroz" 10 College of Agriculture, University of São Paulo, Av. Pádua Dias, 11 - Cx. Postal 9, Piracicaba, 11 SP, Brazil, ZC 13418-900 e-mail: rgtaketani@yahoo.com.br 


\section{Abstract}

14 Background. Mangroves are important coastal ecosystems known for high photosynthetic 15 productivity and ability to support marine food chains through supply of dissolved carbon or 16 particular organic matter. Most of the carbon found in mangroves is produced by its vegetation 17 and is decomposed in root associated sediment. This process involves a tight interaction between 18 microbial populations, litter chemical composition, and environmental parameters. Here, we 19 study the complex interactions found during litter decomposition in mangroves by applying 20 network analysis to metagenomic data.

21 Methods. Leaves of three species of mangrove trees typically found in the southeast of Brazil 22 (Rhizophora mangle, Laguncularia racemosa, and Avicennia schaueriana) were collected in 23 separate litter bags and left on three different mangroves for 60 days. These leaves were 24 subsequently used for metagenome sequencing using Ion Torrent technology. Sequences were 25 annotated in MG-RAST and used for network construction using MENAp.

26 Results. The most common phyla were Proteobacteria (classes Gamma and 27 Alphaproteobacteria) followed by Firmicutes (Clostridia and Bacilli). The most abundant protein 28 clusters were associated with the metabolism of carbohydrates, amino acids, and proteins. Non29 metric multidimensional scaling of the metagenomic data indicated that substrate (i.e., tree 30 species) did not significantly select for a specific community. Both networks exhibited scale-free

31 characteristics and small world structure due to the low mean shortest path length and high 32 average clustering coefficient. These networks also had a low number of hub nodes most of 33 which were module hubs. 
34 Discussion. This study demonstrates that under different environmental pressures (i.e., plant 35 species or mangrove location) the microbial community associated with the decaying material 36 forms a robust and stable network. 


\section{Introduction}

39 Mangroves are highly productive coastal ecosystems (Holguin, Vazquez \& Bashan, 2001) 40 contributing $10-15 \%$ of the global coastal carbon storage (Alongi, 2014). Most of this organic 41 matter (OM) is stored in its sediments (Alongi, Boto \& Tirendi, 1989; Siikamäki, Sanchirico \& 42 Jardine, 2012). However, a significant part of that is exported to surrounding environments as 43 dissolved or as particular OM (Alongi, Boto \& Tirendi, 1989). Most of the carbon found in 44 mangroves is produced by vegetation, although there is also a contribution of water column and 45 sediment organisms to the carbon stock (Holguin, Vazquez \& Bashan, 2001; Kristensen et al., 46 2008).

Litter degradation is a complex multifactorial process dependent on litter chemical composition, environmental parameters and populations of both macro and microorganisms (Schneider et al., 2012). This process is initiated and mediated by litter colonizing microbes (Heijden et al., 2016;

50 Purahong et al., 2016).

52 Efficiency of litter degradation and decomposition is closely linked to organic matter lability 53 (Kristensen et al., 2008, García-Palacios et al., 2016) with differences leading to the formation of 54 separate niches occupied by specific microbes (Frossard et al., 2013). This dynamic process 55 leads to complex interactions between populations with different metabolic capabilities and 56 ecological functions (Dini-Andreote et al., 2014). These interactions can lead to the formation of 57 patterns of co-occurrence (and co-exclusion) between populations that could unveil ecological 58 processes yet unknown (Green et al., 2017). The use of network analysis has unveiled the 59 relationships between populations and functions in the most diverse processes and habitats (Faust 
$60 \&$ Raes, 2012). The interactions between microorganisms happen in a variety of ways such as the

61 flow of energy, matter, and signals leading to the formation of complex ecological networks

62 (Montoya, Pimm \& Sole, 2006). Studying these dynamics is essential to understand the

63 processes that govern ecological networks (Zhou et al., 2011; Faust \& Raes, 2012; Deng et al.,

64 2016). In litter decomposition, the interactions between complementary microbes is required for

65 the decomposition of complex polymers such as cellulose and lignin (Purahong et al., 2016,

66 Purahong et al., 2016).

67

68 This study was designed to study the complex interactions observed during litter decomposition

69 in mangroves by applying network analysis to metagenomic data and to test the hypothesis that

70 in such a complex environment the ecological network formed by these communities is

71 responsible for the homeostasis of the process.

\section{Materials and Methods}

73 Study site and field experiment

74 This study was conducted in three different mangrove sites in the State of São Paulo, Brazil. One

75 in the south of the state located in the city of Cananéia (Can) $\left(25^{\circ} 05^{\prime} 03^{\prime \prime} \mathrm{S}-47^{\circ} 57^{\prime} 75^{\prime \prime} \mathrm{W}\right)$ and two in

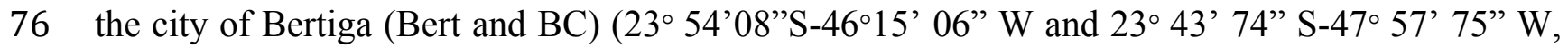

77 respectively) in the center of the state. The former (Can) is a preserved mangrove with no history

78 of anthropogenic impact; the other two are located close to highly urbanized and industrial areas

79 and therefore have high human influence (Andreote et al., 2012). Also, BC had a major oil spill

80 in 1983 from which is still in process of recovery (Andreote et al., 2012). In each of these

81 mangroves, fresh and mature leaves (at the same phenological state) from the three main species 
82 of mangrove trees (Rhizophora mangle, Laguncularia racemosa, and Avicennia schaueriana)

83 were sampled directly from the tree. The chemical composition of these leaves varies between

84 species, $R$. mangle has the lowest hemicellulose and protein content and the highest lignin

85 content, L. racemosa has the highest hemicellulose, and the lowest cellulose content while $A$.

86 schaueriana has the highest cellulose and protein content (see Moitinho et al., 2018 for details).

87 Field sampling was approved by the System of authorization and information in biodiversity 88 (SISBIO \#20366-3).

Sampled leaves were added to sterile nylon litterbags $(25 \times 25 \mathrm{~cm}$, mash size $0.1 \mathrm{~mm})$ containing $300 \mathrm{~g}$ of each plant material and left over the sediment for 60 days during the fall of $2014\left(10^{\text {th }}\right.$ of march to $8^{\text {th }}$ of may). For each plant species, four different litterbags were randomly distributed in a $30.0 \mathrm{~m}^{2}$ area in each mangrove forest. After this time the bags were collected and $100 \mathrm{~g}$ of decomposed material was immediately frozen in liquid nitrogen for DNA extraction.

94 Nucleic acid extraction, processing, and sequencing.

95 The total DNA was extracted from the decaying leaves using RNA PowerSoil® Total RNA Isolation Kit and RNA PowerSoil ${ }^{\circledR}$ DNA Elution Accessory Kit, respectively, following the

97 manufacturer's protocol. DNA quality and quantity were evaluated with the Nanodrop 2000 and by $1 \%$ agarose gel electrophoresis. Metagenomic libraries were constructed using Ion Xpress

99 Plus Fragment Library Kit with Ion Xpress Barcode Adapters following the manufacturer's 100 protocol. Sequencing templates were constructed with Ion PGM Template OT2 400 Kit in an Ion 101 torrent OneTouch 2 equipment. Sequencing was performed using Ion PGM 400pb Sequencing 102 Kit on an Ion Torrent Personal Genome Machine. The sequencing of 21 libraries obtained a total 103 of 9.317 .861 reads with an average of $233 \mathrm{bp}$. 


\section{Sequencing processing and annotation}

105 Metagenomic sequences were uploaded to MG-RAST and were processed using the default 106 parameters and can be found under project number (mpg13300). All phylogenetic analysis 107 presented here is the result of the Best Hit Classification against the M5NR database using an E108 value cut-off of $10^{-5}$, a minimum identity of $60 \%$ and a minimum alignment of 50 bp (Delmont 109 et al., 2011). The functional annotation was performed by Hierarchical Classification against the

110 Subsystems database using an E-value cut-off of $10^{-5}$, a minimum identity of $60 \%$ and a 111 minimum alignment of 15 amino acids.

\section{Data analysis}

113 In order to reduce the sparsity of the data, low coverage samples $(n<2000)$ were removed and 114 annotation tables were normalized using cumulative-sum scaling (CSS) (Paulson et al., 2013) in 115 Qiime 1.9.1 (Caporaso et al., 2010). In order to identify features (taxa or genes) that could be 116 considered as markers of a certain treatment, data were analyzed using MetagenomeSeq (Paulson 117 et al., 2013). Also, permutational multivariate analysis of variance (Adonis), Non-metric 118 Multidimensional Scaling and Mantel tests were performed within the Vegan package in R 119 (Oksanen, 2010). Mantel test was performed in Qiime (Caporaso et al., 2010).

120 Network analysis was performed on the CSS normalized data using Molecular Ecological

121 Network Analyses Pipeline (MENAp) (Deng et al., 2012). Networks were constructed based on 122 features that were present in at least $70 \%$ of the samples using Pearson correlation matrix. 123 Metagenomic NWs were constructed using a p-value cut-off of 0.01 . The Gephi software 124 (Bastian, Heymann \& Jacomy, 2009) was used to visualize the network graphs. To determine the 
125 role of individual nodes we have applied edge degree, Betweenness, Zi and Pi (Zhou et al., 2010)

126 to describe the properties of each node and plots were produced using ggplot2 (Wickham, 2009).

127 Random networks were generated using the Maslov-Sneppen procedure (Maslov \& Sneppen, 128 2002).

\section{Results}

Site and leaf species effect on microbiome function and composition

131 The community found in the litter samples was homogeneous between plant species and sites

132 (Fig. 1). The most common phyla were Proteobacteria (classes Gamma and Alphaproteobacteria)

133 followed by Firmicutes (Clostridia and Bacilli) (Fig. 1A and B). Most of the reads detected in the

134 libraries belonged to Bacteria. Besides the bacterial phyla, the only phylum with normalized

135 relative abundance above $1 \%$ was the Euryarchaeota. The functional classification of the reads

136 was even more homogeneous than the taxonomic (Fig. 1C). The most abundant protein clusters

137 were associated with the metabolism of carbohydrates, amino acids, and proteins.

138 Non-metric multidimensional scaling (NMDS) of the metagenomic data indicated that substrate

139 (i.e., tree species) did not significantly select for a specific community (Fig. 2A and B). It also

140 showed that different mangroves had a large overlap between them. This pattern was more

141 pronounced in the NMDS based on the functional data (Fig. 2B) than the taxonomic (Fig. 2A).

142 Two-way Adonis $(\mathrm{p}<0.05)$ also confirmed these results. According to this test, neither site nor 143 plant species had a significant effect on the communities' functional profile, while there is a

144 significant effect of site on the taxonomic profile (Pseudo-F=2.39424 R2=0.21981 p=0.020).

145 Despite this slightly different result, the Mantel test indicates a strong $(r=0.86565)$ and 
146 significant $(\mathrm{p}=0.001)$ correlation between functional and taxonomic data. We also tested whether

147 differential features in the data could be differentiated (i.e., substrate, site or substrate+site) using

148 MetagenomeSeq (Paulson et al., 2013). However, no feature was significantly different between

149 treatments.

150

151 Network Analysis

152 The construction of ecological networks was applied to describe the interactions between

153 community features (i.e., taxa or genes). The interactions do not represent close contact between

154 features but their behaviors are significantly correlated. Indeed, correlations exist between

155 different sorts of ecological parameters (e.g., competition, mutualism, predation, environmental

156 overlap). However, due to the complexity of microbial communities and their diminished size,

157 the true nature of such correlations is difficult to understand.

158

159 The network based on the taxonomic classification of the metagenomic data has revealed a 160 complex network with 2783 nodes and 5754 edges (Fig. 3). This network had a high degree of 161 modularity and several dual node subnetworks. Another feature of this NW is the high 162 association of populations of the same phyla.

163 The taxonomic and functional networks exhibited scale-free characteristics, as indicated by $\mathrm{R}^{2}$ of 164 power-law fitting ( 0.83 for the functional network and 0.88 for the taxon network). Randomly 165 rewiring the network connections and calculation of network properties indicated that 166 associations observed deviate from a random association and that these networks exhibit small- 
167 world structure due to the low mean shortest path length and average clustering coefficient (table $1681)$.

169 The analysis of the centrality of individual nodes indicates that each phylum had a distinct role 170 within this network (Fig. S2). Bacteroidetes presented the highest average Betweenness 171 centrality $(\mathrm{BwC})$ of all phyla, followed by Proteobacteria and Chloroflexi. Populations with high $172 \mathrm{BwC}$ have central positions in an NW and cannot be easily removed, whereas low BwC 173 populations can be eliminated from the NW without disrupting the network. Another important 174 observation is the association between taxonomic affiliation, normalized abundance, and BwC.

175 Population with high abundance had the highest $\mathrm{BwC}$ and were affiliated with Bacteroidetes or 176 Proteobacteria.

177 The largest subnetwork was formed by Bacteroidetes. The remaining subnetworks were divided 178 between the other abundant phyla. Most of the subnetworks formed by Proteobacteria were 179 separated between the different classes Proteobacteria (Fig. 4A). The ZP plot (Fig. 4B) indicates 180 that all features present in the network are peripherals $(\mathrm{Zi} \leq 2.5, \mathrm{Pi} \leq 0.62)$, with most of their 181 links inside their modules. Most of them had no links outside their own modules (i.e., Pi=0).

182 There was only one module hub $(\mathrm{Zi}>2.5, \mathrm{Pi} \leq 0.62)$, no connectors $(\mathrm{Zi} \leq 2.5, \mathrm{Pi}>0.62)$ or 183 network hubs $(\mathrm{Zi}>2.5, \mathrm{Pi}>0.62)$. This module hub was classified as Pseudomonas OTU 184 closely related to $P$. aeruginosa. This result indicates low connectivity in the network.

185 The ecological network constructed from the functional assignment of the metagenomic 186 sequences show a larger and more complex net of interconnected nodes (Fig. 5) with 4030 nodes 187 and 12648 edges. The clustering by classification is not apparent in this network. Randomly 188 rewiring the network connections and calculation of network properties indicate that associations 189 observed deviate from a random association (table 1). 
190 The functional network was highly connected, indicating a strong redundancy of nodes. As such,

191 it was difficult to identify among the most frequent functional groups one with highest BwC

192 (Fig. S4).

193 The functional network shows a clear relationship between abundance and BwC, however this is

194 not the case at a taxonomy level (Fig. 6A). However, nodes with higher BwC had a central role

195 in the network (as module hub, connectors or network hubs) (Fig. 6B). The ZP plot (Fig. 6B)

196 indicates that most of the features present in the network are peripherals $(\mathrm{Zi} \leq 2.5, \mathrm{Pi} \leq 0.62)$,

197 with most of their links inside their modules. However, links with high BwC held important

198 positions in these networks as module hubs $(\mathrm{Zi}>2.5, \mathrm{Pi} \leq 0.62)$ and connectors $(\mathrm{Zi} \leq 2.5, \mathrm{Pi}>$

199 0.62). Additionally, no network hub $(\mathrm{Zi}>2.5, \mathrm{Pi}>0.62)$ was present in these networks. This

200 result ndicates a low connectivity in the network with a lot of small independent modules.

\section{Discussion}

202 Environmental dynamics pose a challenge to the survival of nutrient cycling organisms in 203 estuarine environments (Holguin, Vazquez \& Bashan, 2001). In the case of mangroves, 204 sediments can be dry or submerged as well as subjected to fresh or marine environments 205 (Bouillon et al., 2004), which results in a complex microbial assemblage (Freschet et al., 2013; 206 Miura et al., 2015; Moitinho et al., 2018). In this study, we have applied litterbag experiments to 207 unravel the effects that plant species has on the microorganisms that colonize their decaying 208 leaves and to identify how the environmental characteristics affect this process. Interestingly, the 209 community composition did not present high variation when we looked at broader taxonomic 210 ranks (such as phylum and class). This apparent stability was observed regardless of the factor 211 analyzed (i.e., plant species or mangrove site). This effect was stronger in the functional than 
212 taxonomic classification. However, the contrasting pattern between functional and taxonomic

213 classification is relatively common and has been observed in many environments (Costello et al.,

214 2012; Delmont et al., 2012; Taketani et al., 2014). Furthermore, the communities found in the

215 decaying leaves were different from those usually found in mangrove sediments that have a high

216 abundance of sulfur reducing Deltaproteobacteria (Andreote et al., 2012; Varon-Lopez et al.,

217 2014) while leaves were dominated by Gamma and Alphaproteobacteria. This must be

218 determined by the fact that the environment in which the decomposition takes place is not

219 suitable for these organisms due to the higher concentration of $\mathrm{O}_{2}$ which also prevents the

220 presence of methanogenic archaeal populations (Dias et al., 2011; Mendes et al., 2012). This

221 suggests that these organisms may come from aerobic sources such as air, water, and leaf.

222 The small variation in the composition reflected in NMDS and Adonis patterns which were

223 found to be not significant. This is indicative that despite the variation in environmental

224 characteristics that the community profile is quite stable. Alternatively, we can propose that the

225 populations that inhabit this material might be selected to withstand this variation.

226 Fluctuations of fresh and marine waters in estuarine ecosystems result in spatial and temporal 227 variation of microbial communities (Guo et al., 2017), as such, mangrove litter is subjected to a 228 large range of biotic and abiotic environmental factors.

229 Plant material with different chemical properties has been shown to have only a minor effect on 230 the bacterial community composition of mangroves (Tláskal et al., 2018). This explanation is 231 supported in our study as we did not find any functional feature or taxonomic group that was 232 differentially abundant in any leaf species or mangrove site. 
233 The functional and taxonomic networks presented a great number of co-occurring nodes. The

234 network constructed based on these data presented scale-free characteristics and this type of

235 network is considered very resistant to disturbances and the removal of nodes (Green et al.,

236 2017), and indicates a relatively stable microbial community structure.

237

238 These networks also exhibit small-world structure, which indicates that nodes are accessible to 239 every other node through a short path (Layeghifard, Hwang \& Guttman, 2017). These networks 240 are believed to be highly coordinated while allowing for a high degree of functional 241 specialization into clustered units (Watts \& Strogatz, 1998; Green et al., 2017). However, a 242 small-world structure is common in large networks (Green et al., 2017).

243 The taxonomy based network formation indicates that there is a tight link between phylogeny 244 and lifestyle since the co-occurrence patterns indicate a preference for similar environmental 245 conditions (Fig. 4A). The correlations between nodes of the same taxonomic groups might be 246 related to similar lifestyles shared by closely related taxa (Philippot et al., 2010). Despite the

247 possibility that minor differences between such taxa might lead to distinct ecological strategies 248 or lifestyles (Fraser et al., 2009; Denef et al., 2010), it can be speculated that there is some 249 degree of redundancy in this networks which would aid in the stability of the process.

250 The Bacteroidetes are recognized as consumers of complex polysaccharides in marine 251 environments and their genomes have a large number of genes related to glycoside hydrolase 252 (GH) families (Bauer et al., 2006). Hence, these bacteria might have an important role in the leaf 253 degradation despite the expected role of fungi in this process (Hu et al., 2017; Tláskal et al., 254 2018). This result indicates that in mangrove sediments, bacteria (especially Bacteroidetes) 255 might have an important role in the decomposition, possibly due to the lower cost of 
256 reproduction of this bacterial taxa, that are considered r-strategists (Hu et al., 2017), in the

257 energy limited anaerobic sediments (Taketani et al., 2010b).

258 The second phylum with the highest $\mathrm{BwC}$ were the Proteobacteria which is a very versatile 259 group (Cobo-Simón \& Tamames, 2017) and very abundant in marine environments and 260 mangroves (Taketani et al., 2010a; Andreote et al., 2012; Varon-Lopez et al., 2014). In terrestrial 261 ecosystems, Alpha-, Beta- and Gammaproteobacteria were found to be prevalent in the initial 262 phases of litter degradation due to their fast growth (DeAngelis et al., 2013) and they also 263 become more prominent over time in phyllospheric communities (Vojtěch, Vorískivá \& 264 Baldrian, 2016). This wide range of lifestyles contributed to the broad dispersal of BwC 265 observed in figure 4.

266 The topological role of individual nodes (Zi-Pi plot) indicated that a Pseudomonas 267 (Gammaproteobacteria) is the only taxon that has an important position in this network as a 268 module hub. Hubs have a central role in a network and/or module (Jiang et al., 2015). Hence, this 269 pseudomonad is a key node within a module despite its low abundance and BwC. However, 270 scale-free networks usually display only a small portion of hubs (Green et al., 2017) which 271 contributes to its robustness.

272 However, the role of individual nodes in the functional network was slightly different than 273 observed in the taxonomic analysis. All of the broad functional groups had a similar average 274 BwC which indicates that they have similar importance within the network. Besides, nodes with 275 higher $\mathrm{BwC}$ were identified as hubs (module hubs and connectors) which indicates that the 276 removal of these would affect the structure of the network (Deng et al., 2012). However, since 277 within these nodes there is a mixture of different taxa that are likely to respond differently to 278 perturbation, there is a chance that the higher robustness of the taxonomic network would aid the 
279 community to endure stresses. Hence, there might be an important role of functional redundancy

280 to the stability of the community present in mangrove litter (Strickland et al., 2009; Banerjee et

281 al., 2016) which would aid in maintaining the efficient decomposition of litter (Kaiser et al., 282 2014)

283

284 Conclusions

285 This study has shown that the community present in mangrove plant's decaying material is stable 286 despite differences in plant species or mangrove location. These communities form a tight 287 network that is robust and resistant to disturbances and therefore capable of withstanding the 288 constantly changing environment that mangrove ecosystems present.

\section{Acknowledgments}

290 The authors thank João Luiz da Silva, Vanessa Nessner Kavamura, Natália Franco Taketani and 291 Fabio Sérgio Paulino Silva for their support during sampling. 


\section{References:}

294

295 Alongi DM. 2014. Carbon Cycling and Storage in Mangrove Forests. Annual Review of Marine Science

296 6:195-219. DOI: 10.1146/annurev-marine-010213-135020.

297 Alongi DM., Boto KG., Tirendi F. 1989. Effect of the exported mangrove litter on bacterial productivity 298 and dissolved organic-carbon fluxes in the adjacent tropical nearshore sediments. Marine Ecology299 Progress Series 56:133-144.

300 Andreote FD., Jiménez DJ., Chaves D., Dias ACF., Luvizotto DM., Dini-Andreote F., Fasanella CC., 301 Lopez MV., Baena S., Taketani RG., de Melo IS. 2012. The microbiome of Brazilian mangrove sediments as revealed by metagenomics. PloS one 7:e38600. DOI: 10.1371/journal.pone.0038600.

Banerjee S., Kirkby CA., Schmutter D., Bissett A., Kirkegaard JA., Richardson AE. 2016. Network analysis reveals functional redundancy and keystone taxa amongst bacterial and fungal communities during organic matter decomposition in an arable soil. Soil Biology and Biochemistry 97:188-198.

307

308

309

310

311 DOI: 10.1016/j.soilbio.2016.03.017.

Bastian M., Heymann S., Jacomy M. 2009. Gephi: An Open Source Software for Exploring and Manipulating Networks.

Bauer M., Kube M., Teeling H., Richter M., Lombardot T., Allers E., Würdemann CA., Quast C., Kuhl H., Knaust F., Woebken D., Bischof K., Mussmann M., Choudhuri J V., Meyer F., Reinhardt R., Amann RI., Glöckner FO. 2006. Whole genome analysis of the marine Bacteroidetes " Gramella forsetii " reveals adaptations to degradation of polymeric organic matter. 8:2201-2213. DOI: 10.1111/j.1462-2920.2006.01152.x.

Bouillon S., Moens T., Overmeer I., Koedam N., Dehairs F. 2004. Resource utilization patterns of epifauna from mangrove forests with contrasting inputs of local versus imported organic matter. Marine Ecology Progress Series 278:77-88. DOI: 10.3354/meps278077.

Caporaso JG., Kuczynski J., Stombaugh J., Bittinger K., Bushman FD., Costello EK., Fierer N., Peña AG., Goodrich JK., Gordon JI., Huttley GA., Kelley ST., Knights D., Koenig JE., Ley RE., 
319

320

321

322

323

324

325

326

327

328

329

330

331

332

333

334

335

336

337

338

339

340

341

342

343

344

Lozupone CA., Mcdonald D., Muegge BD., Pirrung M., Reeder J., Sevinsky JR., Turnbaugh PJ., Walters WA., Widmann J., Yatsunenko T., Zaneveld J., Knight R. 2010. QIIME allows analysis of high- throughput community sequencing data. Nature Methods 7:335-336. DOI: 10.1038/nmeth0510-335.

Cobo-Simón M., Tamames J. 2017. Relating genomic characteristics to environmental preferences and ubiquity in different microbial taxa. BMC genomics 18:1-11. DOI: 10.1186/s12864-017-3888-y.

Costello EK., Stagaman K., Dethlefsen L., Bohannan BJM., Relman D a. 2012. The application of ecological theory toward an understanding of the human microbiome. Science (New York, N.Y.) 336:1255-62. DOI: 10.1126/science.1224203.

DeAngelis KM., Chivian D., Fortney JL., Arkin AP., Simmons B., Hazen TC., Silver WL. 2013. Changes in microbial dynamics during long-term decomposition in tropical forests. Soil Biology and Biochemistry 66:60-68. DOI: 10.1016/j.soilbio.2013.06.010.

Delmont TO., Malandain C., Prestat E., Larose C., Monier J., Simonet P., Vogel TM., Lyon EC De. 2011. Metagenomic mining for microbiologists. The ISME Journal 5:1837-1843. DOI: 10.1038/ismej.2011.61.

Delmont TO., Prestat E., Keegan KP., Faubladier M., Robe P., Clark IM., Pelletier E., Hirsch PR., Meyer F., Gilbert J a., Le Paslier D., Simonet P., Vogel TM. 2012. Structure, fluctuation and magnitude of a natural grassland soil metagenome. The ISME journal 6:1677-87. DOI: 10.1038/ismej.2011.197.

Denef VJ., Kalnejais LH., Mueller RS., Wilmes P., Baker BJ., Thomas BC., VerBerkmoes NC., Hettich RL., Banfield JF. 2010. Proteogenomic basis for ecological divergence of closely related bacteria in natural acidophilic microbial communities. Proceedings of the National Academy of Sciences 107:2383-2390. DOI: 10.1073/pnas.0907041107.

Deng Y., Jiang Y-H., Yang Y., He Z., Luo F., Zhou J. 2012. Molecular ecological network analyses. BMC bioinformatics 13:113. DOI: 10.1186/1471-2105-13-113.

Deng Y., Zhang P., Qin Y., Tu Q., Yang Y., He Z., Schadt CW., Zhou J. 2016. Network succession reveals the importance of competition in response to emulsified vegetable oil amendment for 

2920.12981.

347 Dias ACF., Dini-Andreote F., Taketani RG., Tsai SM., Azevedo JL., Melo IS., Andreote FD. 2011. 348 Archaeal communities in the sediments of three contrasting mangroves. Journal of Soils and 349 Sediments. DOI: 10.1007/s11368-011-0423-7.

350 Dini-Andreote F., Triado X., Casamayor EO., Elsas JD Van., Falca J., de Cassia Pereira e Silva M., 351 Triado-Margarit X., Casamayor EO., van Elsas JD., Salles JF. 2014. Dynamics of bacterial 352 community succession in a salt marsh chronosequence: evidences for temporal niche partitioning. The ISME Journal 8:1989-2001. DOI: 10.1038/ismej.2014.54.

354 Faust K., Raes J. 2012. Microbial interactions: from networks to models. Nature reviews. Microbiology 10:538-50. DOI: 10.1038/nrmicro2832.

Fraser C., Alm EJ., Polz MF., Spratt BG., Hanage WP. 2009. The Bacterial Species Challenge : Ecological Diversity. Science 323:741-746. DOI: 10.1126/science.1159388.

358 Freschet GT., Cornwell WK., Wardle D a., Elumeeva TG., Liu W., Jackson BG., Onipchenko VG., 359 Soudzilovskaia N a., Tao J., Cornelissen JHC. 2013. Linking litter decomposition of above- and below-ground organs to plant-soil feedbacks worldwide. Journal of Ecology 101:943-952. DOI: $10.1111 / 1365-2745.12092$.

Frossard A., Gerull L., Mutz M., Gessner MO. 2013. Litter supply as driver of microbial activity and community structure on decomposing leaves: a test in experimental streams. Applied and biology : new strategies for dealing with biological complexity. Synthese. DOI: 10.1007/s11229016-1307-6.

370 Guo X., Niu Z., Lu D., Feng J., Chen Y., Tou F., Liu M. 2017. Bacterial community structure in the 
371

372

373

374

375

376

377

378

379

380

381

382

383

384

385

386

387

388

389

390

391

392

393

394

395

396

intertidal biofilm along the Yangtze. Marine Pollution Bulletin 124:314-320. DOI: 10.1016/j.marpolbul.2017.07.051.

Heijden MGA Van Der., Bruin S De., Luckerhoff L., Logtestijn RSP Van., Schlaeppi K. 2016. A widespread plant-fungal-bacterial symbiosis promotes plant biodiversity, plant nutrition and seedling recruitment. Isme $J$ 10:389-399. DOI: 10.1038/ismej.2015.120.

Holguin G., Vazquez P., Bashan Y. 2001. The role of sediment microorganisms in the productivity, conservation, and rehabilitation of mangrove ecosystems: An overview. Biology and Fertility of Soils 33:265-278. DOI: 10.1007/s003740000319.

Hu Z., Xu C., McDowell NG., Johnson DJ., Wang M., Luo Y., Zhou X., Huang Z. 2017. Linking microbial community composition to C loss rates during wood decomposition. Soil Biology and Biochemistry 104:108-116. DOI: 10.1016/j.soilbio.2016.10.017.

Jiang Y., Sun B., Li H., Liu M., Chen L., Zhou S. 2015. Aggregate-related changes in network patterns of nematodes and ammonia oxidizers in an acidic soil. Soil Biology and Biochemistry 88:101-109.

DOI: $10.1016 /$ j.soilbio.2015.05.013.

Kaiser C., Franklin O., Dieckmann U., Richter A. 2014. Microbial community dynamics alleviate stoichiometric constraints during litter decay. Ecology Letters 17:680-690. DOI: 10.1111/ele.12269.

Kristensen E., Bouillon S., Dittmar T., Marchand C. 2008. Organic carbon dynamics in mangrove ecosystems: A review. Aquatic Botany 89:201-219. DOI: 10.1016/j.aquabot.2007.12.005.

Layeghifard M., Hwang DM., Guttman DS. 2017. Disentangling Interactions in the Microbiome: A Network Perspective. Trends in Microbiology 25:217-228. DOI: 10.1016/j.tim.2016.11.008.

Maslov S., Sneppen K. 2002. Specificity and Stability in Topology of Protein Networks. Science 296:910-913. DOI: 10.1126/science.1065103.

Mendes LW., Taketani RG., Navarrete AA., Tsai SM. 2012. Shifts in phylogenetic diversity of archaeal communities in mangrove sediments at different sites and depths in southeastern Brazil. Research in microbiology 163:366-77. DOI: 10.1016/j.resmic.2012.05.005.

Miura T., Niswati A., Swibawa IG., Haryani S., Gunito H. 2015. Diversity of Fungi on Decomposing 
Leaf Litter in a Sugarcane Plantation and Their Response to Tillage Practice and Bagasse Mulching:

398

399 Implications for Management Effects on Litter Decomposition. :646-658. DOI: 10.1007/s00248-

400 015-0620-9.

Moitinho MA., Bononi L., Souza DT., Melo IS., Taketani RG. 2018. Bacterial succession decreases

401

402 network complexity during plant material decomposition in mangroves. Microbial ecology. DOI: 10.1007/s00248-018-1190-4.

Montoya M., Pimm SL., Sole R V. 2006. Ecological networks and their fragility. Nature 442:259-264.

$404 \quad$ DOI: $10.1038 /$ nature04927.

405 Oksanen P. 2010. Vegan 1.17-0.

406 Paulson JN., Stine OC., Bravo HC., Pop M. 2013. Differential abundance analysis for microbial marker407 gene surveys. Nature methods 10:1200-2. DOI: 10.1038/nmeth.2658.

408 Philippot L., Andersson SGE., Battin TJ., Prosser JI., Schimel JP., Whitman WB., Hallin S. 2010. The 409 ecological coherence of high bacterial taxonomic ranks. Nature Reviews Microbiology 8:523-529. $410 \quad$ DOI: $10.1038 /$ nrmicro2367.

411 Prosser JI., Bohannan BJM., Curtis TP., Ellis RJ., Firestone MK., Freckleton RP., Green JL., Green LE., 412 Killham K., Lennon JJ., Osborn AM., Solan M., van der Gast CJ., Young JPW. 2007. Essay - The 413 role of ecological theory in microbial ecology. Nature Reviews Microbiology 5:384-392.

414 Purahong W., Wubet T., Lentendu G., Schloter M., Pecyna MJ., Kapturska D., Hofrichter M. 2016. Life 415 in leaf litter : novel insights into community dynamics of bacteria and fungi during litter 416 decomposition. Molecular ecology 25:4059-4074. DOI: 10.1111/mec.13739.

417 Schneider T., Keiblinger KM., Schmid E., Sterflinger-Gleixner K., Ellersdorfer G., Roschitzki B., Richter 418 A., Eberl L., Zechmeister-Boltenstern S., Riedel K. 2012. Who is who in litter decomposition? 419 Metaproteomics reveals major microbial players and their biogeochemical functions. The ISME 420 journal 6:1749-62. DOI: 10.1038/ismej.2012.11.

421 Siikamäki J., Sanchirico JN., Jardine SL. 2012. Global economic potential for reducing carbon dioxide 422 emissions from mangrove loss. Proceedings of the National Academy of Sciences of the United 
424 Strickland MS., Lauber C., Fierer N., Bradford M a. 2009. Testing the functional significance of 425 microbial community composition. Ecology 90:441-51.

426 Taketani RG., Franco NO., Rosado AS., van Elsas JD. 2010a. Microbial community response to a 427 simulated hydrocarbon spill in mangrove sediments. Journal of microbiology (Seoul, Korea) 48:7428 15. DOI: $10.1007 / \mathrm{s} 12275-009-0147-1$.

429 Taketani RG., Kavamura VN., Mendes R., Melo IS. 2014. Functional congruence of rhizosphere 430 microbial communities associated to leguminous tree from Brazilian semiarid region. Environmental $431 \quad$ Microbiology Reports. DOI: 10.1111/1758-2229.12187.

432 Taketani RG., Yoshiura CA., Dias ACF., Andreote FD., Tsai SM. 2010b. Diversity and identification of 433 methanogenic archaea and sulfate-reducing bacteria in sediments from a pristine tropical mangrove. Antonie van Leeuwenhoek 97:401-411. DOI: 10.1007/s10482-010-9422-8.

435

436

437

438

439

440

441

442

443

444

445

446

447 448

Tláskal V., Zrustova P., Vrska T., Baldrian P. 2018. Bacteria associated with decomposing dead wood in a natural temperate forest. FEMS microbiology ecology:1-13. DOI: 10.1093/femsec/fix157.

Varon-Lopez M., Dias ACF., Fasanella CC., Durrer A., Melo IS., Kuramae EE., Andreote FD. 2014. Sulphur-oxidizing and sulphate-reducing communities in Brazilian mangrove sediments. Environmental microbiology 16:845-55. DOI: 10.1111/1462-2920.12237.

Vojtěch T., Vorískivá J., Baldrian P. 2016. Bacterial succession on decomposing leaf litter exhibits a specific occurrence pattern of cellulolytic taxa and potential decomposers of fungal mycelia. FEMS Microbiology Ecology 92:1-10. DOI: 10.1093/femsec/iw177.

Watts DJ., Strogatz SH. 1998. Collective dynamics of "small-world" networks. Nature 393:440-442.

Wickham H. 2009. ggplot2: elegant graphics for data analysis. Springer New York.

Zhou J., Deng Y., Luo F., He Z., Tu Q., Zhi X. 2010. Functional molecular ecological networks. MBio 1:e00169-10. DOI: 10.1128/mBio.00169-10.Editor.

Zhou J., Deng Y., Luo F., He Z., Yang Y. 2011. Phylogenetic molecular ecological network of soil microbial communities in response to elevated CO2. MBio 2:e0122-11. DOI: 
$449 \quad 10.1128 / \mathrm{mBio} .00122-11$. Editor.

450 


\section{Figure 1}

Classification of metagenomic sequences from samples of litterbags left on mangrove sediments.

A - classification of sequences to the level of phylum; B - classification of sequences from

Proteobacteria to the level of class; $C$ - classification of sequences in functional SEED subsystems. 


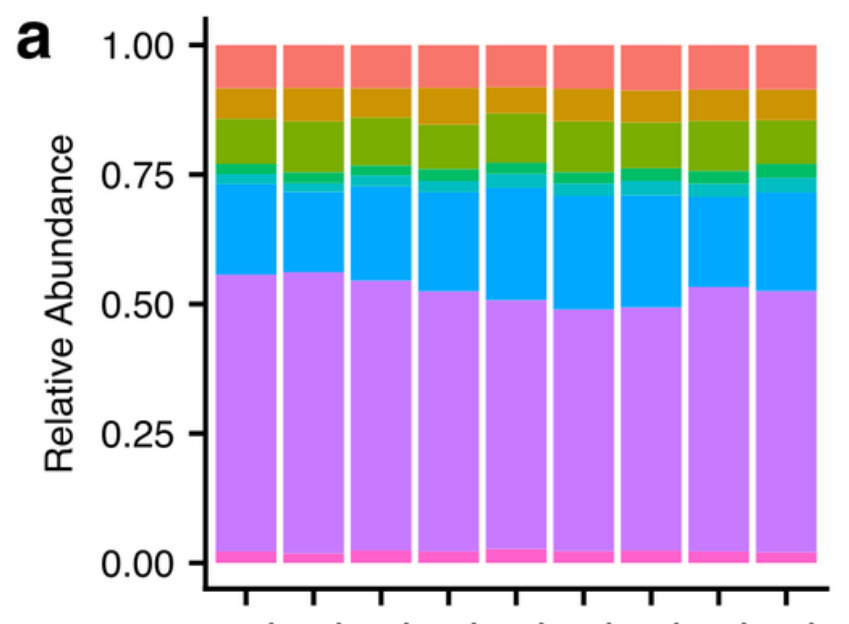

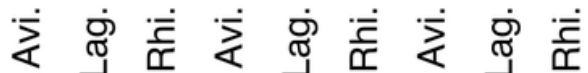

O

b

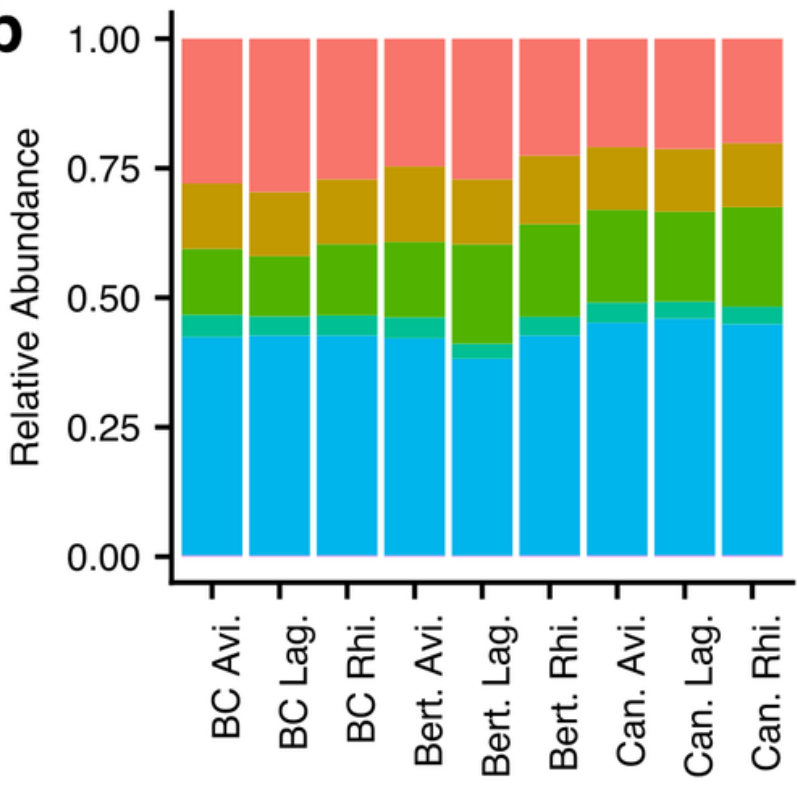

Phylum

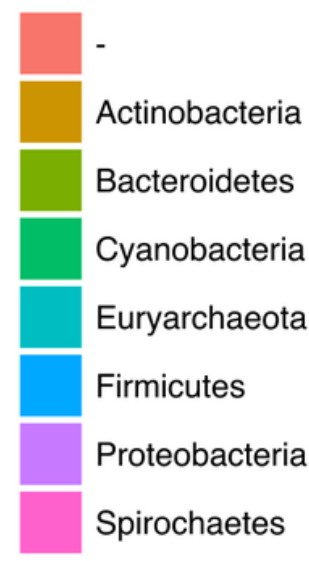

Class

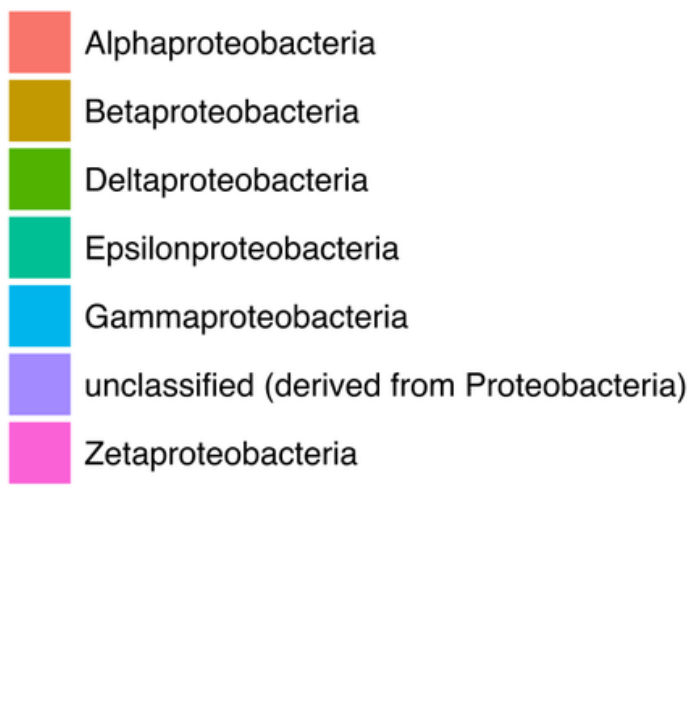

Level1
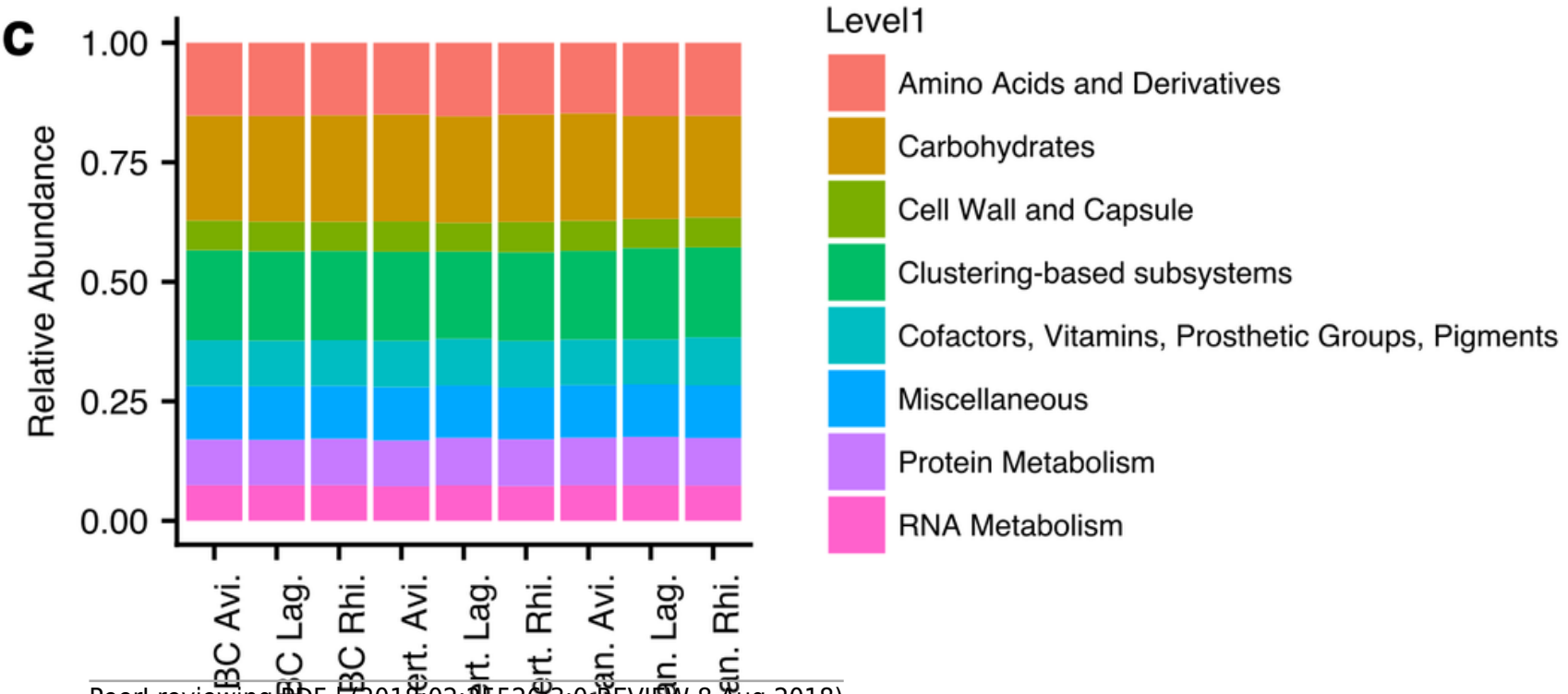
Figure 2

Non-metric multidimensional scaling plots (NMDS) of metagenomic data based on MGRAST classification of sequences obtained from litterbags left on mangrove sediments.

A - NMDS of the taxonomic classification of metagenomic data; B - NMDS of functional classification of the metagenomic data. Samples are colored as displayed on the legend.
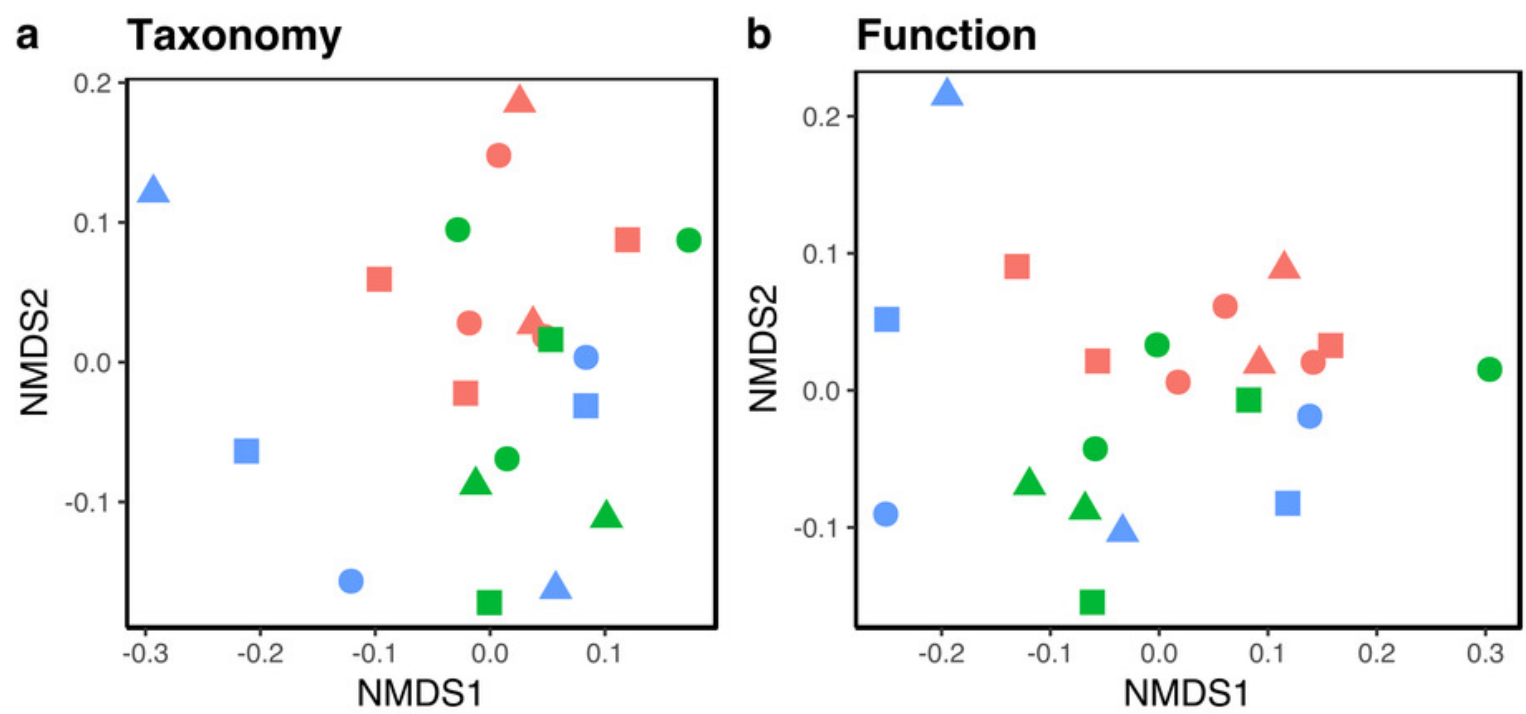

Site

BC

Bertioga

Cananeia

Plant

Avicennia

A Laguncularia

- Rhizophora 


\section{Figure 3}

Ecological network based on the taxonomic classification of the mangrove trees litter decomposition metagenomic samples.

Node size is proportional to the Node Betweenness. For a high-resolution version of the figure check figure S1.

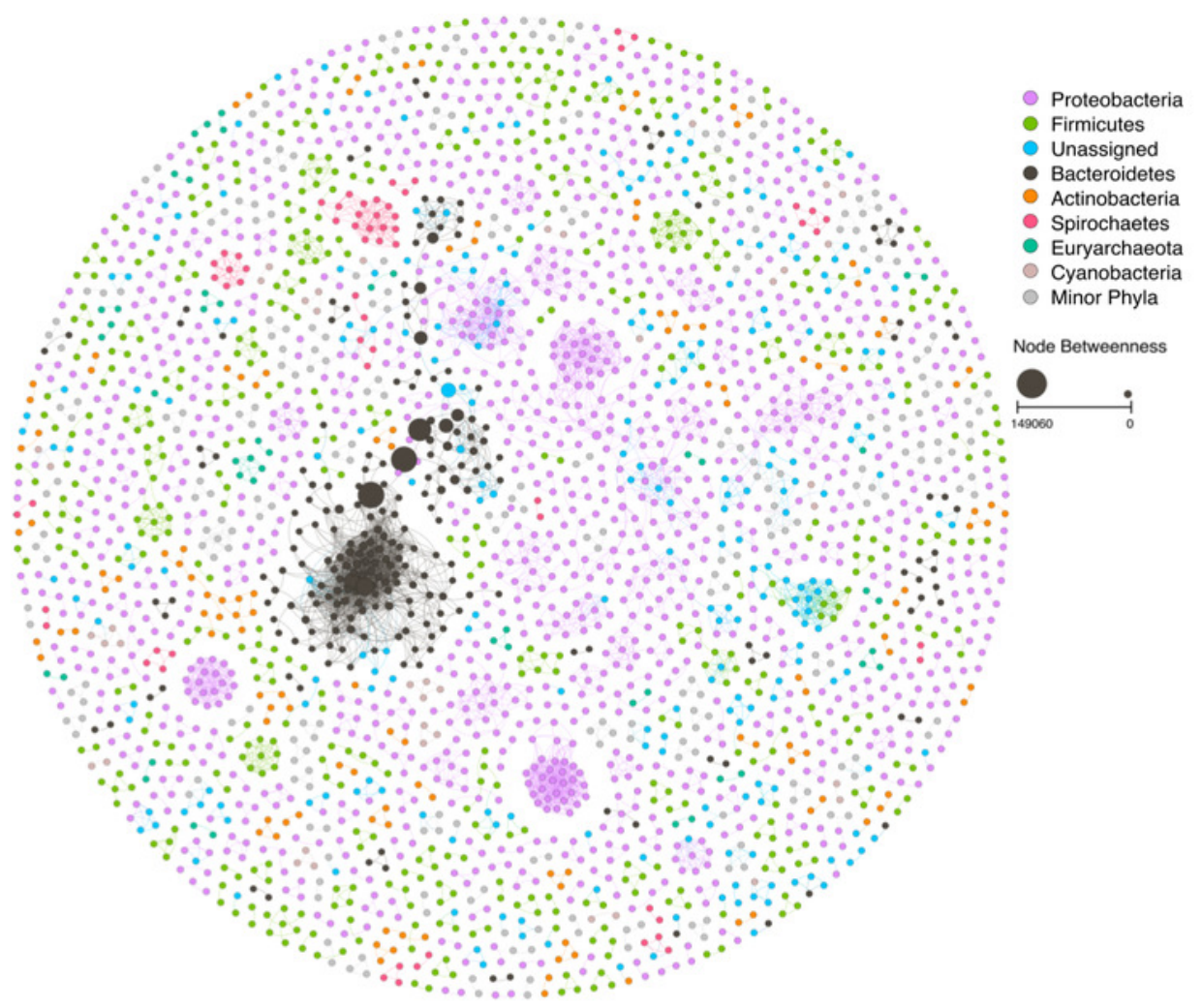




\section{Figure 4}

Properties of each node as represented by their role within the network.

A - relationship between node betweeness, abundance and taxonomic assignment; $B$ -relationship between within-module connectivity ( $\mathrm{Zi})$ and among-module connectivity (Pi), node betweeness, and taxonomic assignment.
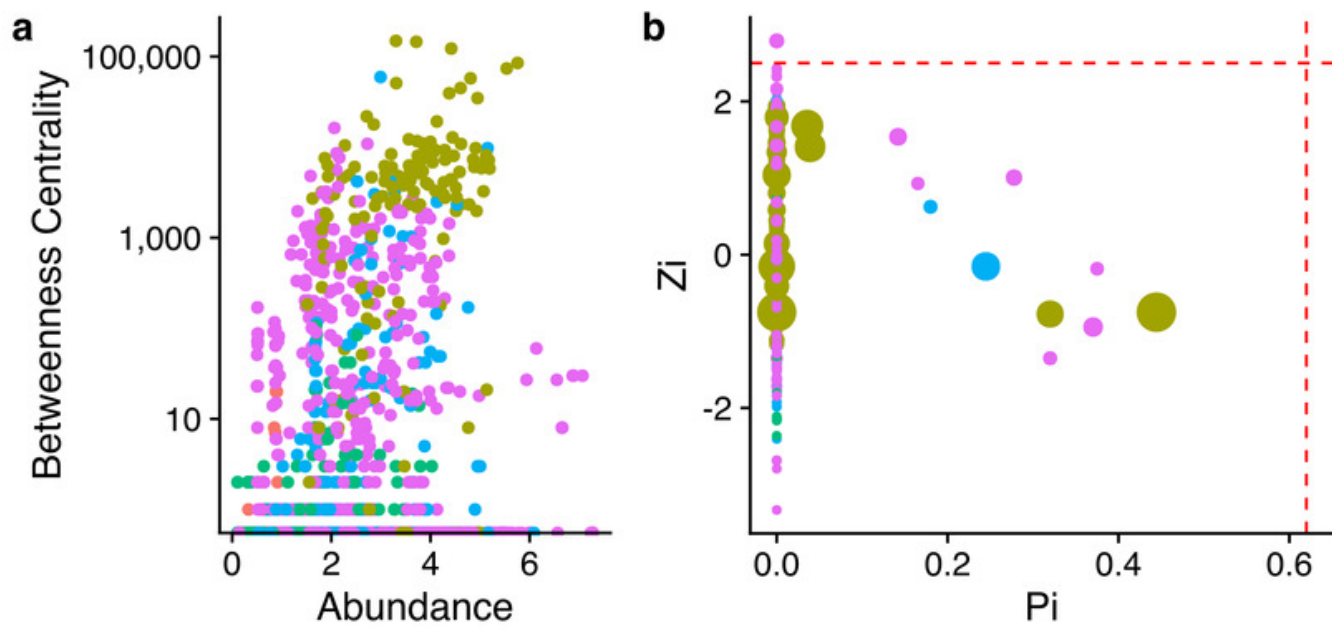

Betweenness Centrality

- $0 \mathrm{e}+00$

$5 \mathrm{e}+04$

$1 e+05$

Phylum

- Actinobacteria

- Bacteroidetes

- Firmicutes

- Other

- Proteobacteria Abundance $\mathrm{Pi}$ 


\section{Figure 5}

Ecological network based on the functional classification of the mangrove trees litter decomposition metagenomic samples.

Node size is proportional to the Edge Betweenness. For a high-resolution version of the figure check figure S3. 


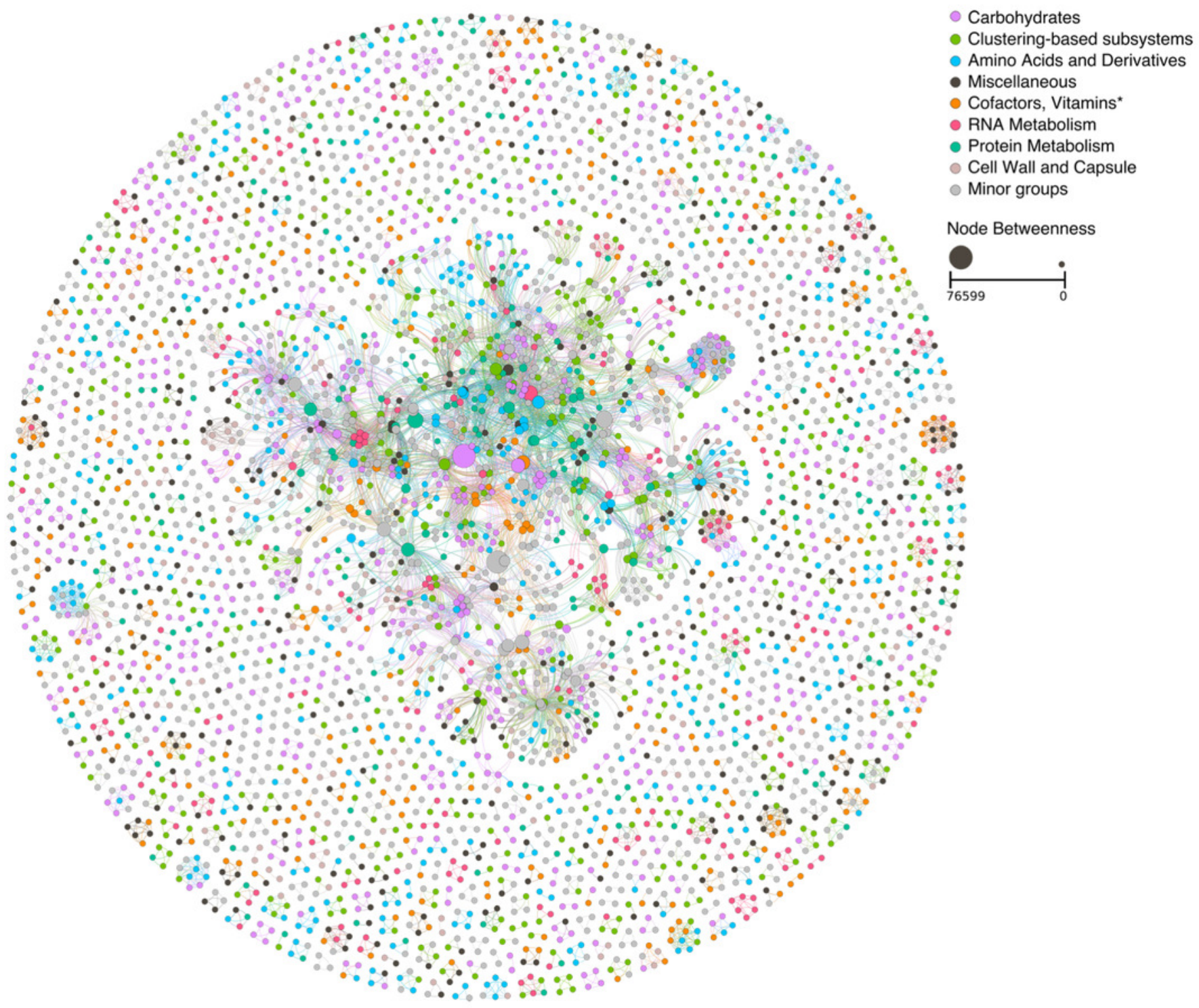




\section{Figure 6}

Properties of each node as represented by their role within the network.

A - relationship between node betweeness, abundance and functional assignment; B -relationship between within-module connectivity ( $\mathrm{Zi})$ and among-module connectivity (Pi), node betweenness, and functional assignment.
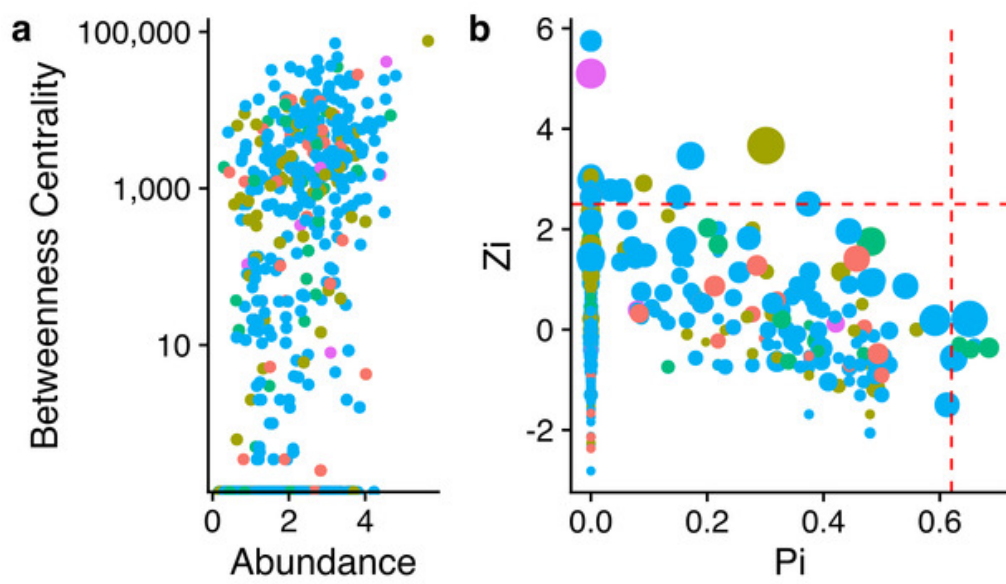

MG-RAST Level 1

- Amino Acids and Derivatives

- Carbohydrates

- Cofactors, Vitamins, Prosthetic Groups, Pigments

- Other

- RNA Metabolism

Betweenness Centrality

- 0

- 20000

40000

60000 


\section{Table $\mathbf{1}$ (on next page)}

Indexes based on ecological network analysis of metagenomic data from decomposing leaves of mangrove trees and random trees constructed based on this data. 
1 Table 1: Indexes based on ecological network analysis of metagenomic data from decomposing leaves of mangrove trees and random trees constructed based on this data

3

\begin{tabular}{|c|c|c|c|c|}
\hline \multirow[b]{2}{*}{ Network Indexes } & \multicolumn{2}{|c|}{ Taxonomic } & \multicolumn{2}{|c|}{ Functional } \\
\hline & $\begin{array}{l}\text { Empirical } \\
\text { Network }\end{array}$ & $\begin{array}{l}100 \text { Random } \\
\text { Networks }\end{array}$ & $\begin{array}{l}\text { Empirical } \\
\text { Network }\end{array}$ & $\begin{array}{l}100 \text { Random } \\
\text { Networks }\end{array}$ \\
\hline Modularity(fast_greedy) & 0.927 & $0.490 \pm 0.003$ & 0.781 & $0.363 \pm 0.002$ \\
\hline Lubness & 1.000 & $1.000 \pm 0.000$ & 1.000 & $1.000 \pm 0.000$ \\
\hline Hierarchy & 0.000 & $0.000 \pm 0.000$ & 0.000 & $0.000 \pm 0.000$ \\
\hline Efficiency & 0.827 & $0.999 \pm 0.000$ & 0.985 & $0.999 \pm 0.000$ \\
\hline Connectedness (Con) & 0.007 & $0.851 \pm 0.011$ & 0.093 & $0.902 \pm 0.008$ \\
\hline Transitivity (Trans) & 0.723 & $0.028 \pm 0.002$ & 0.453 & $0.018 \pm 0.001$ \\
\hline Reciprocity & 1.000 & $1.000 \pm 0.000$ & 1.000 & $1.000 \pm 0.000$ \\
\hline Density (D) & 0.001 & $0.001 \pm 0.000$ & 0.002 & $0.002 \pm 0.000$ \\
\hline $\begin{array}{l}\text { Centralization of eigenvector } \\
\text { centrality (CE) }\end{array}$ & 0.171 & $0.160 \pm 0.011$ & 0.174 & $0.141 \pm 0.011$ \\
\hline $\begin{array}{l}\text { Centralization of stress centrality } \\
\text { (CS) }\end{array}$ & 0.038 & $0.214 \pm 0.014$ & 18.19 & $0.220 \pm 0.013$ \\
\hline $\begin{array}{l}\text { Centralization of betweenness } \\
\text { (CB) }\end{array}$ & 0.002 & $0.035 \pm 0.002$ & 0.009 & $0.029 \pm 0.002$ \\
\hline Centralization of degree (CD) & 0.019 & $0.019 \pm 0.000$ & 0.021 & $0.021 \pm 0.000$ \\
\hline $\begin{array}{l}\text { Harmonic geodesic distance } \\
\text { (HD) }\end{array}$ & 320.933 & $4.864 \pm 0.059$ & 45.375 & $4.251 \pm 0.031$ \\
\hline Geodesic efficiency (E) & 0.003 & $0.206 \pm 0.002$ & 0.022 & $0.235 \pm 0.002$ \\
\hline Average path distance (GD) & 0.03 & $3.784 \pm 0.061$ & 0.464 & $3.662 \pm 0.036$ \\
\hline $\begin{array}{l}\text { Average clustering coefficient } \\
\text { (avgCC) }\end{array}$ & 0.524 & $0.012 \pm 0.002$ & 0.636 & $0.012 \pm 0.001$ \\
\hline
\end{tabular}

